\title{
Sodium and Potassium Content of Meals Served in University Canteens
}

\author{
Maria Inês Barbosa ${ }^{a} \quad$ Alexandra Fernandes ${ }^{a}$ Carla Gonçalves $^{a}$ \\ Maria João Pena ${ }^{a, b}$ Patrícia Padrão ${ }^{a, c}$ Olívia Pinhoa, ${ }^{a}$ Pedro Moreira ${ }^{a, c, e}$ \\ ${ }^{a}$ Faculdade de Ciências da Nutrição e Alimentação da Universidade do Porto, Porto, Portugal; ${ }^{\text {b} F a c u l d a d e ~ d e ~}$ \\ Medicina, Universidade do Porto, Porto, Portugal; ' $E P I U n i t$ - Instituto de Saúde Pública, Universidade do Porto,

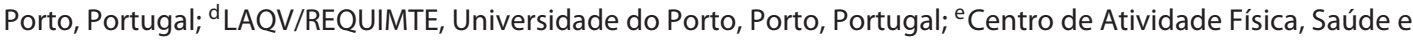 \\ Lazer, Universidade do Porto, Porto, Portugal
}

\section{Keywords}

Sodium · Potassium · Meals · University canteens · Atomic emission spectrometry

\begin{abstract}
A high sodium intake is associated with high blood pressure, an important risk factor for noncommunicable diseases (NCDs). In contrast, the ingestion of high levels of potassium counteracts this negative effect of high sodium intake on blood pressure, thus reducing the sodium-to-potassium ratio. The aim of this work was to determine the sodium and potassium content of meals served in university canteens in Portugal. The analysis included 35 samples of soup and 35 samples of main dish collected at 5 random days from a total of 7 university canteens. The samples were analyzed for sodium and potassium by atomic emission spectrometry technique. On average, a meal (soup and main dish) had a sodium content of 1,069.4 mg (mean sodium content was 671.4 $\pm 374.5 \mathrm{mg} /$ portion in the main dish and $398.0 \pm 153.0 \mathrm{mg} /$ portion in the soup) and a potassium content of 1,004 mg (mean potassium content was $731.4 \pm 385.9 \mathrm{mg} / \mathrm{serving}$ in the main dish and $272.6 \pm 272.6 \mathrm{mg} /$ serving in the soup). Our results revealed that with a single university meal, students can reach $53 \%$ of the maximum daily value recommended
\end{abstract}

for sodium and $27 \%$ of the minimum daily value recommended for potassium. An investment to decrease sodium and increase potassium in meals served is imperative in order to prevent NCDs.

(c) 2018 The Author(s). Published by S. Karger AG, Basel on behalf of Escola Nacional de Saúde Pública

\section{Teor de sódio e potássio em refeições servidas em cantinas universitárias}

\section{Palavras chave}

Sódio · Potássio · Refeições · Cantinas universitárias · Espectroscopia emissão atómica

\section{Resumo}

Uma elevada ingestão de sódio está associada à hipertensão, um importante fator de risco para doenças crónicas não transmissíveis (DCNT). Em contraste, a ingestão de níveis elevados de potássio contrabalança esse efeito negativo da elevada ingestão de sódio na pressão arterial, reduzindo, assim, a relação sódio/potássio. O objetivo deste trabalho foi determinar o teor de sódio e potássio de refeições servidas em cantinas universitárias em Portu-

\section{KARGER}

E-Mail karger@karger.com www.karger.com/pjp (c) 2018 The Author(s). Published by S. Karger AG, Basel on behalf of Escola Nacional de Saúde Pública Karcer

0 pen access

This article is licensed under the Creative Commons Attribution NonCommercial-NoDerivatives 4.0 International License (CC BYNC-ND) (http://www.karger.com/Services/OpenAccessLicense) Usage and distribution for commercial purposes as well as any distribution of modified material requires written permission.
Carla Gonçalves

Faculdade de Ciências da Nutrição e Alimentação da Universidade do Porto Rua Roberto Frias

PT-4200-465 Porto (Portugal)

E-Mail carlagoncalves.pt@gmail.com 
gal. A análise incluiu 35 amostras de sopa e 35 amostras de prato principal recolhidas em 5 dias aleatórios de um total de 7 cantinas universitárias. As amostras foram analisadas para sódio e potássio pela técnica de espectroscopia de emissão atómica. Uma refeição (sopa e prato principal) apresentou em média um teor de sódio de 1.069,4 mg (teor médio de sódio foi $671,4 \pm 374,5 \mathrm{mg} /$ porção no prato principal e $398,0 \pm 153,0 \mathrm{mg} /$ porção na sopa) e um teor de potássio de $1.004 \mathrm{mg}$ (teor médio de potássio foi de $731,4 \pm 385,9 \mathrm{mg} /$ porção no prato principal e $272,6 \pm$ $272,6 \mathrm{mg}$ /porção na sopa). Os resultados mostraram que, com uma única refeição universitária, os alunos podem atingir $53 \%$ do valor máximo diário recomendado para o sódio e $27 \%$ do valor mínimo diário recomendado para o potássio. Um investimento para diminuir o sódio e aumentar o potássio nas refeições servidas é imperativo para prevenir as DCNT.

(c) 2018 The Author(s). Published by S. Karger AG, Basel on behalf of Escola Nacional de Saúde Pública

\section{Introduction}

Noncommunicable diseases (NCDs) are the leading cause of death globally [1]. In Portugal, NCDs account for about $86 \%$ of all deaths [2] and the prevalence of hypertension in adults is $42.2 \%$ [3]. Several population-based studies worldwide have documented the association between high sodium intake and hypertension [4].

The salt from processed foods and the salt added to food during the cooking process are the main sources of sodium intake [5]. Besides the increase of blood pressure, high salt intake is associated with an increased risk of gastric cancer [6,7], development of cardiovascular damages [8], increased left ventricular mass $[9,10]$, occurrence of cerebrovascular disease [11], and increased arterial stiffness [12, 13].

It was documented that a 5-gram reduction in daily salt intake by the general population could prevent one and a quarter million deaths from stroke and almost three million deaths from cardiovascular disease each year [14]. On the opposite, potassium intake can mitigate the negative effects of high sodium intake [15], namely because of its antihypertensive effects. It has been described that potassium decreases intravascular volume, partly through decreased sodium reabsorption, i.e., increased urinary sodium excretion [16]. Likewise, potassium is an essential nutrient needed for maintenance of total body fluid volume, acid and electrolyte balance, and normal cell function [17].
A low potassium intake has been reported as a major public health problem in the USA, with negative effects on cardiovascular disease, renal stone development, and bone mineral density $[15,18]$. On the other hand, if recommendations for both sodium and potassium are achieved, the sodium-to-potassium ratio should be close to $1.0 \mathrm{mmol} / \mathrm{mmol}(0.59 \mathrm{mg} / \mathrm{mg})$, which may be reached with an adequate intake of fruit and vegetables [19]. High dietary sodium-to-potassium ratios have been linked to a higher risk of NCDs, including coronary heart disease and stroke [20]. Therefore, potassium is seen as one of the key nutrients to prevent NCDs [21].

Potassium is mostly found in a variety of unrefined foods, particularly in fruit and vegetables. Food processing reduces the amount of potassium in many food products, so a diet rich in processed foods and poor in fresh fruit and vegetables is often associated with a low potassium diet [22].

The WHO established recommendations for both sodium and potassium in order to reduce blood pressure and risk of cardiovascular disease, stroke, and coronary heart disease in adults. The WHO recommends a maximum daily intake of 2,000 mg of sodium ( $5 \mathrm{~g} /$ day of salt) [23] and suggested a potassium intake of at least 3,510 $\mathrm{mg} /$ day for the adult population [21].

The canteens are the place chosen by university students for eating most meals out of home, and are also a privileged place to promote healthy eating habits [24,25]. The aim of this study was to determine sodium and potassium content in university canteen meals.

\section{Material and Methods}

\section{Sample Collection}

The samples were collected at 7 canteens from a Portuguese university, on 5 random days, between February and May 2015. One sample of soup and one sample of main dish were collected at each visit at the canteens. As the units presented 5 types of main dishes each day (meat, fish, vegetarian, and diet), on the fifth day of sample collection, a type of main dish was repeated, randomly chosen. The final sample consisted of 35 soups and 35 main dishes.

The samples were collected at lunchtime. Samples were weighed in the kitchen and each component was weighed separately in the case of the main dish (e.g., first rice was weighed, then salad, then meat, etc.). Soup and main dishes were transported to the laboratory in separate hermetic plastic bags in a refrigerated cooler box.

The samples were prepared on the same day of collection and only the edible part was considered after deboning fish and meat. Soups were homogenized with a hand blender (Electric Co 450 $\left.\mathrm{W}^{\circledR}\right)$, while the main dish components were mixed up with an elec- 
tric food chopper (Moulinex $700 \mathrm{~W}^{\circledR}$ ) into a homogenous mass of food. The homogenized mass obtained from samples was distributed on PTFE $60 \mathrm{~mL}$ containers and stored in a freezer $\left(-18^{\circ} \mathrm{C}\right)$ until it was used.

\section{Chemical Analysis}

Sodium and potassium content was determined by atomic emission spectrometry (AES).

\section{Reagents and Standard Solutions}

All reagents were of analytical grade and solutions were prepared with deionized water, obtained from Seralpur PRO $90 \mathrm{CN}$ and Seradest LFM 20 water purification system. For the analysis of sodium by AES, sodium standard solution (1,000 ppm) was supplied by JenWay (England), potassium standard solution $(1,000$ ppm) was supplied by JenWay (England), and nitric acid 70\% $\left(\mathrm{HNO}_{3}\right)$ was purchased from Sigma (USA). Solutions used for calibration curves were stored in the refrigerator. Standard solutions were prepared daily from a 1,000 ppm stock solution, with the following concentrations: $0.2,0.5,1.0,2.5$, and $5.0 \mathrm{ppm}$. Standard solutions were read on the photometer before sample readings and a standard solution was read for verification every 10 readings of samples. All PTFE materials were cleaned, bathed in $10 \% \mathrm{HNO}_{3}$ overnight, and rinsed twice with double distilled water.

\section{Analysis by AES}

The samples were analyzed by AES by a flame photometer (PFP7, JenWay, UK). The samples were analyzed in duplicate, with three readings of each extraction. A portion of $2 \mathrm{~g}$ of the sample was weighed (KERN ALS 120-4 ${ }^{\circledR}$, Germany) and then $2 \mathrm{~mL}$ of $\mathrm{HNO}_{3}$ were added. The mixture was then manually shaken carefully every $10 \mathrm{~min}$ for $90 \mathrm{~min}$. After this time, the mixture was filled up with deionized water to $45 \mathrm{~mL}$ and homogenized using an Ultraturrax (Ystral ${ }^{\circledR}$, The Netherlands) and shaken vigorously every $5 \mathrm{~min}$ for $30 \mathrm{~min}$. Then, $12 \mathrm{~mL}$ of solution centrifuged (Labofuge 6000 , Haerus, Germany) at 4,000 rpm for $10 \mathrm{~min}$. Finally, $1 \mathrm{~mL}$ of supernatant was diluted up to $40 \mathrm{~mL}$ and a reading was taken.

\section{Statistical Analysis}

The analysis of the data was performed using the Statistics ${ }^{\circledR}$ SPSS software (version 22.0) for Microsoft Windows ${ }^{\circledR}$. The data were presented in mg per $100 \mathrm{~g}$ of meal and in mg per serving, as mean and standard deviation (mean $\pm \mathrm{SD}$ ). Each canteen was assigned an encoding letter (A through $G$ ).

The Kolmogorov-Smirnov test was used to test the normality of the variables, presented as mean $\pm \mathrm{SD}$. One-way ANOVA test was performed to verify the differences in the content of both minerals between the units (Table 1 ) and between different types of main dish (Table 2 ). A $p$ value $<0.05$ was considered as significant.

\section{Results}

Results are organized in two tables. Table 1 shows the analysis for each canteen. The sodium and potassium concentration $(\mathrm{mg} / 100 \mathrm{~g})$, sodium-to-potassium ratio $(\mathrm{mg} / \mathrm{mg})$, size of serving portion $(\mathrm{g})$, and the sodium and potassium concentration per serving were expressed.

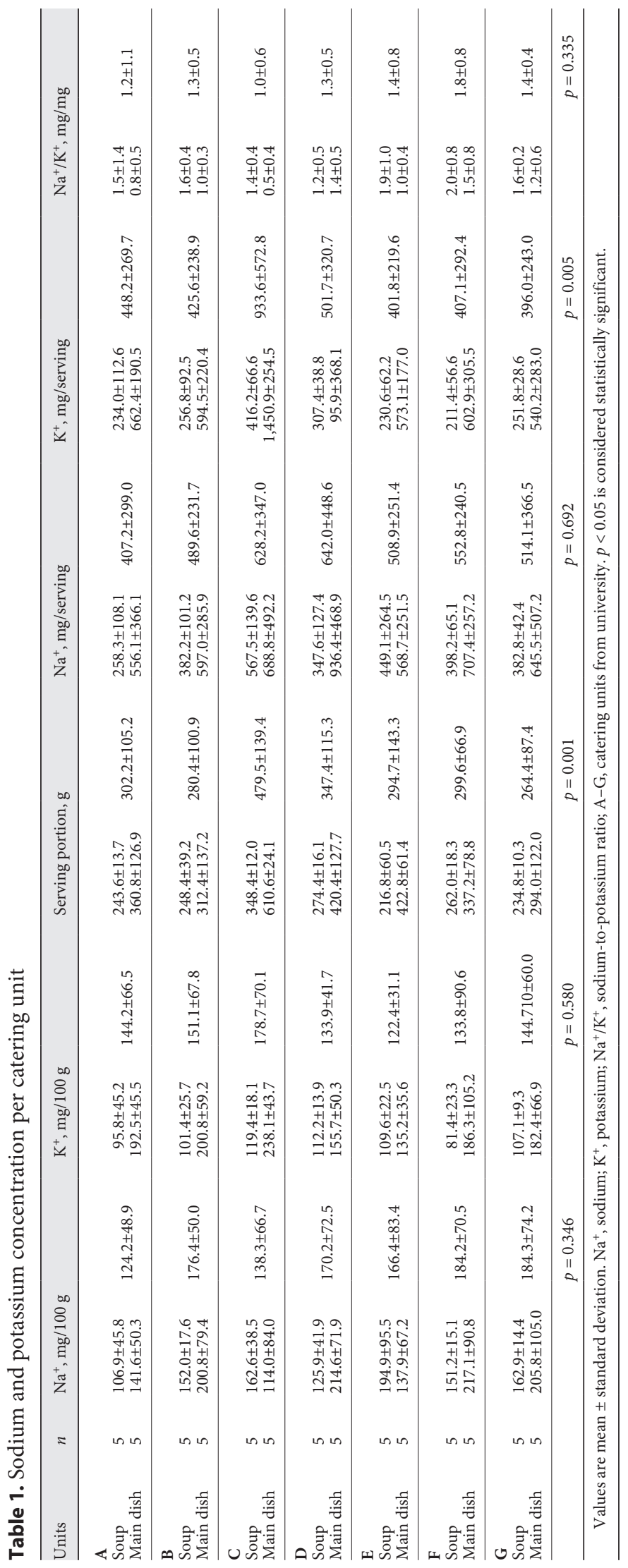

Sodium and Potassium Content of Meals Served in University Canteens
Port J Public Health DOI: $10.1159 / 000488074$ 
Table 2. Sodium and potassium concentration per meal component

\begin{tabular}{|c|c|c|c|c|c|c|c|c|c|c|c|c|c|}
\hline & $n$ & $\begin{array}{l}\mathrm{Na}^{+}, \\
\mathrm{mg} / 100 \mathrm{~g}\end{array}$ & $p$ & $\begin{array}{l}\mathrm{K}^{+}, \\
\mathrm{mg} / 100 \mathrm{~g}\end{array}$ & $p$ & $\begin{array}{l}\text { Serving } \\
\text { portion, } g\end{array}$ & $p$ & $\begin{array}{l}\mathrm{Na}^{+}, \\
\mathrm{mg} / \text { serving }\end{array}$ & $p$ & $\begin{array}{l}\mathrm{K}^{+} \text {, } \\
\mathrm{mg} / \text { serving }\end{array}$ & $p$ & $\begin{array}{l}\mathrm{Na}^{+} / \mathrm{K}^{+} \\
\mathrm{mg} / \mathrm{mg}\end{array}$ & $p$ \\
\hline Main dish & 35 & $176.0 \pm 83.2$ & \multirow{6}{*}{0.069} & $184.4 \pm 64.1$ & \multirow{6}{*}{0.269} & $394.0 \pm 138.7$ & \multirow{6}{*}{$<0.001$} & $671.4 \pm 374.5$ & \multirow{6}{*}{$<0.001$} & $731.4 \pm 385.9$ & \multirow{6}{*}{0.909} & $1.1 \pm 0.6$ & \multirow{6}{*}{0.603} \\
\hline Meat & 11 & $152.1 \pm 98.3$ & & $194.2 \pm 75.6$ & & $367.2 \pm 158.3$ & & $487.9 \pm 372.3$ & & $729.8 \pm 484.1$ & & $0.9 \pm 0.6$ & \\
\hline Fish & 10 & $218.4 \pm 93.2$ & & $208.1 \pm 53.1$ & & $383.4 \pm 118.6$ & & $814.4 \pm 369.4$ & & $793.5 \pm 306.8$ & & $1.1 \pm 0.5$ & \\
\hline Diet & 6 & $145.4 \pm 55.1$ & & $170.9 \pm 74.5$ & & $411.0 \pm 153.9$ & & $606.2 \pm 333.4$ & & $734.4 \pm 509.3$ & & $1.1 \pm 0.8$ & \\
\hline Vegetarian & 8 & $178.5 \pm 46.7$ & & $151.5 \pm 42.8$ & & $431.5 \pm 139.5$ & & $793.9 \pm 354.1$ & & $653.7 \pm 264.1$ & & $1.2 \pm 0.4$ & \\
\hline Soup & 35 & $150.9 \pm 49.9$ & & $103.8 \pm 25.5$ & & $261.2 \pm 48.4$ & & $398.0 \pm 153.8$ & & $272.6 \pm 272.6$ & & $1.6 \pm 0.8$ & \\
\hline
\end{tabular}

Values are mean \pm standard deviation. $\mathrm{Na}^{+}$, sodium; $\mathrm{K}^{+}$, potassium; $\mathrm{Na}^{+} / \mathrm{K}^{+}$, sodium-to-potassium ratio. $p<0.05$ is considered statistically significant.

These values are presented for soup, main dish, and average meal served in each unit (soup and main dish). In this table, it is seen that the serving portion varied significantly between catering units $(p=0.001)$.

Regarding sodium concentration $(\mathrm{mg} / 100 \mathrm{~g})$ and sodium concentration per serving ( $\mathrm{mg} /$ serving), no statistically significant differences between catering units were found $(p=0.692)$. However, it was noted that the sodium content in the average number of meals (soup + main dish) in each unit ranged between 407.2 and $642 \mathrm{mg} / \mathrm{serv}$ ing. For potassium concentration (mg/100 g), no statistically significant differences between catering units were found $(p=0.580)$, but when the average concentration of potassium per serving ( $\mathrm{mg} /$ serving) was considered, unit $\mathrm{C}$ had the highest concentration with $933.6 \pm 572.8 \mathrm{mg}$, and the unit that had fewer potassium per serving was unit $\mathrm{G}$ with $396.0 \pm 243.0 \mathrm{mg}$ ( $p=0.005)$. Sodium-topotassium ratio did not have statistically significant differences between catering units, and varied between $1.0 \pm$ 0.6 (unit C) and $1.8 \pm 0.8$ (unit F).

Table 2 shows the average values for the main dishes and soups, and also shows sodium, potassium, and sodium-to-potassium ratio values in each type of main dish (meat, fish, diet, and vegetarian). The sodium content of the main dish served in the units was on average $176.0 \pm 83.2 \mathrm{mg} / 100 \mathrm{~g}$. Regarding the sodium content in an average serving of main dish, the mean was $671.4 \pm$ $374.5 \mathrm{mg} /$ serving (corresponding to $1.8 \pm 1.0 \mathrm{~g}$ salt $/ \mathrm{serv}$ ing), without statistically significant differences in sodium $(\mathrm{mg} / 100 \mathrm{~g}$ ) between different types of main dish $(p=0.069)$. Nonetheless, as the size of the serving portion of a meal varied between different types of main dish $(p<0.001)$, it was found that fish and vegetarian dishes were the ones with higher sodium content representing $814.4 \pm 369.4 \mathrm{mg} /$ serving and $793.9 \pm 354.1 \mathrm{mg} /$ serving, respectively.
With regard to soups, the mean sodium content was $150.9 \pm 49.9 \mathrm{mg} / 100 \mathrm{~g}$ and $398.0 \pm 153.8 \mathrm{mg} /$ serving (corresponding to $1.0 \pm 0.4 \mathrm{~g}$ salt/serving). The potassium content of soups was, on average, $103.8 \pm 25.5 \mathrm{mg} / 100 \mathrm{~g}$, while the main dish was $184.4 \pm 64.1 \mathrm{mg} / 100 \mathrm{~g}$. There were no statistically significant differences between the different types of main dish. We verified a sodium-topotassium ratio of 1.1 in main dish and 1.6 in soup. No statistically significant differences were found between different types of main dish.

\section{Discussion}

The main result of this study was the high sodium and the low potassium content, compared to the recommended daily intake, that were found in the components of the meals served in university canteens.

High sodium intake by populations around the world and particularly in Portugal has been the subject of much attention by experts in the field of nutrition and cardiovascular health [26], especially when it comes to eating out of home [27].

The results showed that sodium content in the main dish was, on average, $671.4 \pm 374.5 \mathrm{mg} /$ serving and that fish and vegetarian dishes were those with higher sodium content by serving $(814.4 \pm 3694 \mathrm{mg}$ in fish dish and $793.9 \pm 354.1 \mathrm{mg}$ in vegetarian dish; $p<0.001$ ).

The fish dishes may be the less preferred by university students [28] and eventually, food handlers may feel the need to add more salt in order to make the fish dishes more palatable and consequently more consumed.

Vegetarian dishes usually have vegetables in its composition, whose sodium contribution is virtually nonexistent [29]. However, pickled foods (seitan, soy, and tofu) and other products (e.g., puff pastry, salty cheeses) that 
are widely used in these main dishes, have a fairly high sodium contribution [30,31]. Given the intrinsic sodium content of these foods, the addition of salt during cooking in such dishes should be reconsidered.

Soup had an average of $398.0 \pm 153.8 \mathrm{mg}$ of sodium per serving. The study of Gonçalves et al. [32], held in Portugal, which compared the sodium content of soups before and after adding salt, showed that the sodium content of soups was significantly higher after salt addition. This suggests that the main factor responsible for the sodium levels found in soups is the addition of salt during the cooking process (over $90 \%$ of sodium) [32]. Our results are similar to the results of previous studies $[33,34]$, however with slightly lower sodium content.

Main dish showed higher sodium content than soup (Table 2), probably due to the fact that intrinsic sodium present in foods, such as meat and fish, is higher than sodium intrinsically present in vegetables used for soups [29], other reason could be that the main dishes are more suitable to use condiments (e.g., broths, pre-prepared sauces) which are very rich in sodium $[29,35]$, and finally because the level of salt added in a main dish during cooking could be higher than in soups.

On average, one meal composed of soup and main dish had a sodium content of $1,069.4 \mathrm{mg} /$ serving (corresponding to $2.8 \mathrm{~g}$ of salt/serving). Since the WHO recommends a maximum daily intake of 2,000 $\mathrm{mg}$ of sodium (5 $\mathrm{g}$ of salt), the sodium content of one meal reached about $53 \%$ of the recommended daily intake.

During the visits to the catering units, it was found that the addition of salt was under the responsibility of the chef responsible for seasoning the meals and that the amount of salt added was done by instinct. The amount of added salt is influenced by the taste of the chef; however, many food handlers recognize that they do not taste foods before adding salt [36].

Reducing the addition of salt is controversial, and some people consider that salt is a single ingredient, impossible to replace, being the one that gives flavor to food [37]. A study with Portuguese food handlers showed that many of the food handlers were aware of the recommended salt intake values and health problems associated with excessive salt intake. They were sensitive to reducing the salt content of foods produced but referred that the greatest difficulties in salt reduction were the opinion and knowledge of consumers and food handlers [36]. Thus, it is important to educate consumers and food handlers, so that actions to reduce the amount of salt added to meals start to be effective.

Sodium and Potassium Content of Meals

Served in University Canteens
The replacement of salt with herbs and spices is a possible strategy to gradually reduce the salt added to meals. Herbs may positively influence health, either by giving flavor, aroma, and color to meals or by offering beneficial properties for human health [38].

A strategy that could decrease the high variability among sodium content between canteens could be the use of a standard measure of salt to be added to each component of the meal that respects the daily sodium recommendations. Another way could be the implementation of a fast and easy device that informs the food handler about the amount of salt present in food.

Salt reduction must be done without causing significant changes in the salt perception and hedonic perception of consumers. In complex dishes (where all ingredients contribute to the flavor, such as soups), sodium content may be reduced by about 30\% without causing significant changes in the salt perception $[39,40]$. This suggests that a reduction of added salt in this order of magnitude may not interfere with the sensory level, and it is one possible measure to be taken to fight the high sodium levels.

Regarding potassium levels, main dishes had higher potassium values than soup ( $\mathrm{mg} / 100 \mathrm{~g}$ ), which was unexpected, because Portuguese soups are considered comfort food rich in boiled vegetables. Soup is often described as an important source of vitamins and minerals, such as potassium [41]. The role of the potassium supplier depends on a food matrix rich in vegetables and, in some cases, pulses.

The average potassium values found in the analyzed soups were lower than the potassium content of soups described in the Portuguese food composition table [29], suggesting that our soups could have less vegetables and pulses in their composition. A study analyzing 14 soups of scholar meals [34] reported a higher potassium content than our study, which supports the supposition that soups analyzed in our study had an insufficient amount of vegetables. Main dishes had a higher potassium content than soups, maybe due to the presence of animal products (meat and fish), which were important sources of potassium in addition to the vegetables also served in the main dish.

It is also worth noting that in some units, the sodiumto-potassium ratio of soups was almost twice the ideal ratio, which is supposed to be approximately 1.0, which confirms the idea that soups had much more sodium and less potassium than they should have. Also, the ratio was higher in soup than it was in main dishes. 
Our findings revealed an amount of 1,004 mg of potassium, considering soup and main dish, which corresponds to $27 \%$ of the WHO daily intake recommendation for potassium. A study addressing the eating habits of Portuguese university students showed a low intake of fruit and vegetables, and that many of the students did not eat soup daily [42]. Therefore, the amount of potassium ingested by students can be significantly lower than potassium available in meals if they do not eat soup.

The results obtained emphasize the need to consolidate or increase potassium availability in these meals, in order to promote potassium intake in the population, through foods rich in this mineral. The best way to increase potassium intake is to privilege the consumption of fruit and vegetables [43], which itself may have other beneficial effects on health given its content in micronutrients, fiber, and antioxidants [43, 44], without significantly increasing the energy intake or undesirable nutrients.

The amount of vegetables added to the soup and the main dish could be more generous, and the portions served more homogeneous among the units in order to increase potassium availability. Food education sessions for consumers of the canteens could also be an improvement in order to sensitize them to the importance of the consumption of vegetables, pulses, and fruit and conse- quently encourage the consumption of the various components of the meal. Conducting training sessions for professionals of the units reinforces the principles mentioned above.

\section{Conclusion}

In conclusion, the average amount of sodium of a meal served in university canteens corresponds to $53 \%$ of the daily sodium intake recommendation, whereas potassium levels found in these meals correspond to $27 \%$ of the daily potassium intake recommendation. Consumers of meals in university canteens can easily exceed the maximum daily intake for sodium. On the other hand, the potassium recommendation could be difficult to achieve if consumers do not eat soup. An investment by catering companies and social services in training their human resources is imperative in order to increase their awareness of the issue of decreasing salt addition and increasing vegetable availability.

\section{Acknowledgments}

We thank especially the Social Services of the university for the authorization of the study.

\section{References}

1 World Health Organization: Global Status Report on Noncommunicable Diseases. Geneva: WHO; 2010.

2 World Health Organization: Noncommunicable Diseases (NCD): Country Profiles. Geneva: WHO; 2014.

3 Polonia J, Martins L, Pinto F, Nazare J: Prevalence, awareness, treatment and control of hypertension and salt intake in Portugal: changes over a decade. The PHYSA study. J Hypertens 2014;32:1211-1221.

4 Reddy V, Sridhar A, Machado RF, Chen J: High sodium causes hypertension: evidence from clinical trials and animal experiments. J Integr Med 2015;13:1-8.

5 The Caroline Walker Trust: Eating Well for Looked After Children and Young People: Nutritional and Practical Guidelines: Report of an Expert Working Group. Herts, UK: The Caroline Walker Trust; 2001.

6 Sugimura T, Wakabayashi K: Gastric carcinogenesis: diet as a causative factor. Med Oncol Tumor Pharmacother 1990;7:87-92.

7 Tsugane S: Salt, salted food intake, and risk of gastric cancer: epidemiologic evidence. Cancer Sci 2005;96:1-6.
-8 Strazzullo P: Salt-sensitivity, hypertension and cardiovascular ageing: broadening our view without missing the point. J Hypertens 2002;20:561-563.

\9 Messerli FH, Aepfelbacher FC: Hypertension and left-ventricular hypertrophy. Cardiol Clin 1995;13:549-557.

10 Schmieder RE, Messerli FH, Ruddel H, Garavaglia $G G$, Grube E, Nunez BD, et al: Sodium intake modulates left ventricular hypertrophy in essential hypertension. J Hypertens Suppl 1988;6:S148-S150.

11 Perry IJ: Dietary salt intake and cerebrovascular damage. Nutrit Metab Cardiovasc Dis 2000;10:229-235.

12 Polónia J, Maldonado J, Ramos R, Bertoquini S, Duro M, Almeida C, et al: Determinação do consumo de sal numa amostra da população portuguesa adulta pela excreção urinária de sódio: sua relação com rigidez arterial. Rev Port Cardiol 2006;25:801-817.

13 Gates PE, Tanaka H, Hiatt WR, Seals DR: Dietary sodium restriction rapidly improves large elastic artery compliance in older adults with systolic hypertension. Hypertension 2004;44:35-41.
14 Strazzullo P, D’Elia L, Kandala NB, Cappuccio FP: Salt intake, stroke, and cardiovascular disease: meta-analysis of prospective studies. BMJ 2009;339:b4567.

15 Whelton PK, He J, Cutler JA, Brancati FL, Appel LJ, Follmann D, et al: Effects of oral potassium on blood pressure: meta-analysis of randomized controlled clinical trials. JAMA 1997;277:1624-1632.

16 Weaver CM: Potassium and health. Adv Nutr 2013;4:368s-377s.

17 Young B: Role of Potassium in Preventive Cardiovascular Medicine. Boston: Kluwer Academic Publishers; 2001.

18 United States Department of Agriculture. Department of Health and Human Services. Dietary Guidelines Advisory Committee. Scientific Report of the 2015 Dietary Guidelines Advisory Committee. Washington, DC: USDA. HHS; 2015.

19 World Health Organization: Diet, Nutrition and the Prevention of Chronic Diseases. Geneva: WHO; 2003 (Technical report series; 916). 
20 Yang Q, Liu T, Kuklina EV, Flanders WD, Hong Y, Gillespie C, et al: Sodium and potassium intake and mortality among US adults: prospective data from the Third National Health and Nutrition Examination Survey. Arch Intern Med 2011;171:1183-1191.

21 World Health Organization: Guideline: Potassium Intake for Adults and Children. Geneva: WHO; 2012.

22 Webster JL, Dunford EK, Neal BC: A systematic survey of the sodium contents of processed foods. Am J Clin Nutr 2010;91:413420.

23 World Health Organization: Guideline: Sodium Intake for Adults and Children. Geneva: WHO; 2012.

24 Lachat CK, Huybregts LF, Roberfroid DA, Van Camp J, Remaut-De Winter AM, Debruyne $P$, et al: Nutritional profile of foods offered and consumed in a Belgian university canteen. Public Health Nutr 2009;12:122128.

25 Fernandez Torres A, Moreno-Rojas R, Camara Martos F: Nutritional content of foods offered and consumed in a Spanish university canteen. Nutr Hosp 2015;31:1302-1308.

26 He FJ, MacGregor GA: A comprehensive review on salt and health and current experience of worldwide salt reduction programmes. J Hum Hypertens 2009;23:363384.

27 Lachat C, Nago E, Verstraeten R, Roberfroid D, Van Camp J, Kolsteren P: Eating out of home and its association with dietary intake: a systematic review of the evidence. Obes Rev 2012;13:329-346.
8 Martinez Alvarez JR, Garcia Alcon R, Villarino Marin A, Marrodan Serrano MD, Serrano Morago L: Eating habits and preferences among the student population of the Complutense University of Madrid. Public Health Nutr 2015;18:2654-2659.

29 Portugal. Ministério da Saúde. Instituto Nacional de Saúde Dr. Ricardo Jorge. Centro de Segurança Alimentar e Nutrição. Tabela da composição de alimentos. Lisboa: INSA; 2007.

30 Weaver CM, Dwyer J, Fulgoni VL 3rd, King JC, Leveille GA, MacDonald RS, et al: Processed foods: contributions to nutrition. Am J Clin Nutr 2014;99:1525-1542.

-31 Dwyer JT, Fulgoni VL 3rd, Clemens RA, Schmidt DB, Freedman MR: Is "processed" a four-letter word? The role of processed foods in achieving dietary guidelines and nutrient recommendations. Adv Nutr 2012;3:536548.

32 Gonçalves C, Silva G, Pinho O, Camelo S, Amaro L, Teixeira VH, et al: Sodium Content in Vegetable Soups Prepared outside the Home: Identifying the Problem. Occupational Safety Hygiene SHO Series. 2012.

33 Reis AT, Toscano MM, Meister MC: Sal em sopas. Segurança e Qualidade Alimentar 2008;4:54-55.

34 Martins BM: Quantificação de sódio e potássio em sopas de ementas escolares do $1^{\circ}, 2^{\circ} \mathrm{e}$ $3^{\circ}$ ciclos. Universidade do Porto; 2012.

$35 \mathrm{Wu}$ Leung WT, Rauanheimo Butrum R, Huang Chang F, Narayana Rao M, Polacchi W: Food Composition Table for Use in East Asia. Rome (Italy): FAO and US Department of Health, Education, and Welfare; 1972.
36 Gonçalves C, Pinho O, Padrão P, Santos C, Abreu S, Moreira P: Knowledge and practices related to added salt in meals by food handlers. Nutrícias (online) 2014;21:14-17.

37 Bourdain A: Kitchen Confidential: Adventures in the Culinary Underbelly. New York, NY: Bloomsbury Publishing; 2007.

38 Tapsell LC, Hemphill I, Cobiac L, Patch CS, Sullivan DR, Fenech M, et al: Health benefits of herbs and spices: the past, the present, the future. Med J Aust 2006;185(4 suppl):S4-S24.

39 Malherbe M, Walsh CM, Van der Merwe CA: Consumer acceptability and salt perception of food with a reduced sodium content. J Fam Ecol Consum Sci 2003;31:12-20.

40 Gonçalves C, Monteiro S, Padrao P, Rocha A, Abreu S, Pinho O, et al: Salt reduction in vegetable soup does not affect saltiness intensity and liking in the elderly and children. Food Nutr Res 2014;58:1-7.

41 Associação Portuguesa de Nutricionistas. Sopas: mais que um alimento, são um prato de saúde. Lisboa: APN; 2013.

42 Martins ML: Hábitos alimentares de estudantes universitários. Porto: Faculdade de Ciências da Nutrição e Alimentação da Universidade do Porto; 2009. Trabalho de investigação.

43 He FJ, MacGregor GA: Beneficial effects of potassium on human health. Physiol Plant 2008; 133:725-735.

$44 \mathrm{Hu}$ D, Huang J, Wang Y, Zhang D, Qu Y: Fruits and vegetables consumption and risk of stroke: a meta-analysis of prospective cohort studies. Stroke 2014;45:1613-1619. 